\title{
Semantic aphasia as a sole manifestation of acute stroke
}

\author{
Fabricio Ferreira de Oliveira', Wagner Mauad Avelar², \\ Denis Bernardi Bichuetti², Andre Carvalho Felício², Luis Fabiano Marin², \\ Marcia Elisabete Morita², William Adolfo Celso dos Santos²
}

The concept of aphasia designates impairment in the symbolic domains of language (vocabulary, semantics, phonology, syntax and morphology) by one or more lesions in the dominant cerebral hemisphere, which may be manifest through spoken and written comprehension and production, but can not be explained by motor or sensory deficits in view of the preservation of phono-articulatory structures, and neither by generalized cognitive deficits (consciousness must be preserved $)^{1}$. Stroke is the leading cause of aphasia, which may be identified in more than $20 \%$ of stroke patients, reaching up to $40 \%$ in the acute phase $e^{2-5}$. These language disturbances may help forecast the vascular territories involved in brain injury ${ }^{6,7}$.

Errors in naming are more frequent when associated to grave mistakes in fluency and comprehension both for oral and written material ${ }^{4,8,9}$, such as in global aphasia, motor aphasia or sensory aphasia. The diagnosis of semantic aphasia may pass unnoticed if a specific assessment is not undertaken, particularly considering that semantic errors may be produced in naming, reading, spelling, copying or drawing from memory ${ }^{8}$. Prognosis is better than for other vascular aphasic syndromes, but may be related to the size of brain injury ${ }^{5,9}$ (including both the infarcted tissues and the hypoperfused areas) and to the presence of cortical involvement ${ }^{5}$, among other factors.

We report the case of a patient who presented with language impairment as the only symptom in the acute stroke phase, leading to a diagnosis of vascular semantic aphasia. The importance of accurate language evaluation for stroke diagnosis will be discussed.

\section{CASE}

A caucasian 81-year-old female patient was admitted to the Emergency Department of Hospital e Maternidade São Camilo (Pompeia) reporting a frequent reading practice, which included books and newspapers. She had a complete high school education. The day before her admittance, she woke up in the morning noticing that the letters of any texts she tried to read were "scrambled", making her reading very difficult. Since there were no other neurological deficits and her vision was allegedly unimpaired (no visual symptoms were acknowledged), she decided to wait for the next day to seek assistance. The patient reported a diagnosis of untreated systemic hypertension, and a 5-cigarette per day smoking habit.

At the Emergency Room, her blood pressure was $140 / 90 \mathrm{mmHg}$, along with a heart rate of $90 \mathrm{bpm}$, normal auscultation of the heart and lungs, and no cervical bruits. On neurological examination she was alert and oriented, with preserved fluency and repetition, and no paraphasias; she had some difficulty naming common objects (she could name a pen, not a clock, but was able to tell the purpose of each object) and recalling her accompanying son's name, and could not tell the names of her daughter or of her 5 grandchildren, though she knew who they were; long-term memory was unimpaired; a harsh difficulty for reading simple texts was presented, and 


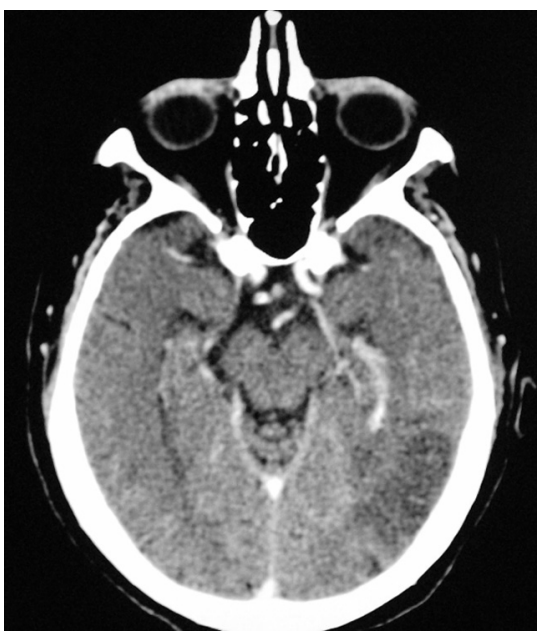

Fig 1. Contrast-enhanced computed tomography of the brain showing a left temporal-occipital infarction in development.

Fig 2. Flair magnetic resonance of the brain displaying a left hemisphere infarction at the temporal-parietal-occipital transition.

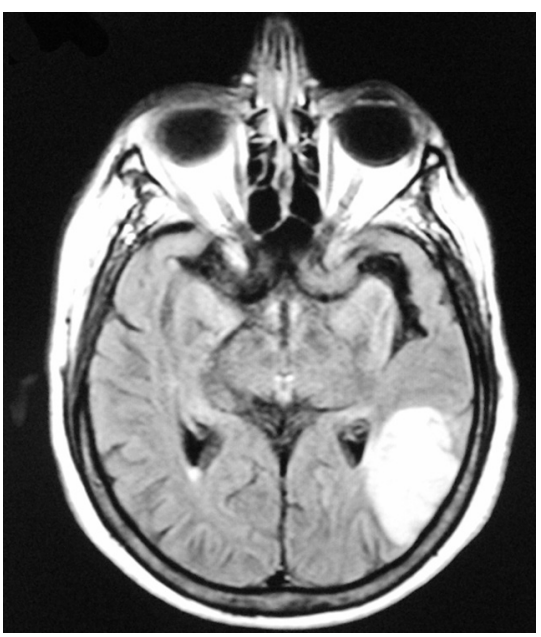

also for writing, including her own name; finger agnosia and left-right disorientation were not noticed; constructional praxis and the ability for calculus were spared; a right homonymous hemianopia was observed, and no motor deficits were present.

Electrocardiogram disclosed a sinus rhythm with unspecific alterations of ventricular repolarization. Computed tomography of the brain showed a left posterior temporal-parietal-occipital infarction which included the angular gyrus and excluded the inferior temporal gyrus (Fig 1). Magnetic resonance of the brain confirmed the same findings (Fig 2).

The patient was then admitted to the Intensive Care Unit, and started on acetyl-salicylic acid at $300 \mathrm{mg}$ per day, along with statin therapy. Anti-hypertensive medications were further ministered during the hospital stay. Significant echocardiographic abnormalities were not found, but some slight carotid irregularities due to the presence of atherosclerotic plaques were discovered by way of doppler ultrasound examination; along with brain imaging and clinical findings, these results suggested a possible atherothrombotic etiology to the stroke, but no obstruction greater than $50 \%$ was present in the arteries of the neck. She still made some semantic mistakes when discharged home a few days later. The patient signed an informed consent for this publication.

\section{DISCUSSION}

Semantic aphasia is also known as anomic aphasia because of the naming impairment which is the prominent characteristic of this form of language disturbance ${ }^{6}$. Our patient presented with semantic aphasia leading to difficulties in reading (alexia) and writing (agraphia), along with homonymous hemianopia which was only verified in the neurological examination, resulting in a diagnosis of acute ischemic stroke. The classical components of Gerstmann's syndrome were not observed, but the involve- ment of the left angular gyrus and its adjacencies could probably explain the signs and symptoms we encountered. Since the lesion size was considered large ${ }^{9}$ (more than $1.5 \mathrm{~cm}$ at any plane), prognosis may not be so good for language performance, but serial evaluation should be further conducted to assess evolution.

The left angular gyrus integrates functions from several other areas of the brain. It may account for left-right orientation, constructional praxis, naming, reading and writing (the spatial representation of words), calculus and finger recognition ${ }^{10}$. We now know that most of these functions are distributed throughout neural networks with parallel processing ${ }^{11}$, and not localized in a specific brain area, but an incomplete form of impairment in spatial representation may be found in patients who have injuries to the angular gyrus or next to it.

The importance of language evaluation in the acute phase may be evidenced by the fact that the National Institutes of Health Stroke Scale (NIHSS) ${ }^{12}$, the most widely used scale for thrombolysis evaluation, may display a loss of up to 8 points if the patient has a severe aphasia 2 points for item $1 \mathrm{~b}$ (level of consciousness questions), 2 points for item 1c (level of consciousness commands), 1 point for item 8 (sensory loss), and 3 points for item 9 (best language). This punctuation could itself substantiate the need for thrombolytic treatment, regardless of the fact that the presence of aphasia alone might justify such therapy even if scores are lower, considering how much it can contribute to worsen the quality of life of stroke patients. Unfortunately, our patient could not receive such treatment because it took her more than 24 hours to seek neurological assistance.

In short, vascular aphasic syndromes are common in the presentation of acute stroke, with or without other signs and symptoms. Proper neurological assessment is essential for their identification and to undertake the correct therapeutical measures. 


\section{REFERENCES}

1. Benson DF. Aphasia. In: Heilman KM, Valenstein E (Eds). Clinical neuropsy chology. New York: Oxford University Press, 1993:17-36.

2. Godefroy O, Dubois C, Debachy B, Leclerc M, Kreisler A. Vascular aphasias: main characteristics of patients hospitalized in acute stroke units. Stroke 2002;33:702-705

3. Laska AC, Hellblom A, Murray V, Kahan T, von Arbin M. Aphasia in acute stroke and relation to outcome. J Intern Med 2001;249:413-422.

4. Mansur LL, Radanovic M, Rüegg D, Mendonca LIZ, Scaff M. Descriptive study of 192 adults with speech and language disturbances. Sao Paulo Med J 2002;120:170-174.

5. Oliveira FF. Afasias vasculares. In: Li LM, Fernandes PT, Martins S, Massaro A (Eds). Neurociências e acidente vascular cerebral. São Paulo: Plêiade, 2009:263-271.
6. Hillis AE. Aphasia: progress in the last quarter of a century. Neurology 2007; 69:200-213.

7. Kreisler A, Godefroy O, Delmaire C, et al. The anatomy of aphasia revisited. Neurology 2000;54:1117-1123.

8. Basso A, Paulin M. Semantic errors in naming, repetition, spelling and drawing from memory: a new Italian case. Neurocase 2003;9:109-117.

9. Oliveira FF, Damasceno BP. Short-term prognosis for speech and language in first stroke patients. Arq Neuropsiquiatr 2009;67:849-855.

10. Adams RD, Victor M, Ropper AH. Principles of neurology. New York: McGraw-Hill, 1997.

11. Damasceno BP. Mente, cérebro e atividade: abordagem neuropsicológica. Rev Bras Neurol 2004;40:5-13.

12. Brott T, Adams HP Jr, Olinger CP, et al. Measurements of acute cerebral infarction: a clinical examination scale. Stroke 1989;20:864-870. 